Original Research Paper

\title{
Association of High-Affinity $F c \varepsilon R I-\beta$ intron 2 for IgE Gene Polymorphism and Atopic Diseases in an Algerian Population
}

\author{
${ }^{1}$ Dahbia Ines Dahmani, ${ }^{2}$ Ikhlass Haj Salem, ${ }^{2}$ Jamila Chakir, ${ }^{3}$ Karima Sifi, \\ ${ }^{4}$ Sellami Abderrahim, ${ }^{5}$ Mounir Zhary Bachtarzi, ${ }^{1}$ Sara Malki, ${ }^{6}$ Laila Rouabah, \\ ${ }^{3}$ Nore-Eddine Abadi, ${ }^{1}$ Mehdioui Hacene, ${ }^{1}$ Mohamed Bougrida and ${ }^{7}$ Mahmoud Rouabhia \\ ${ }^{1}$ Research Laboratory of Metabolic Diseases, Faculty of Medicine, University of Constantine-3, Algeria \\ ${ }^{2}$ Centre de Recherche, Institut Universitaire de Cardiologie et de Pneumologie de Québec, Université Laval, Québec, Canada \\ ${ }^{3}$ Research Laboratory of Biology and Molecular Genetics, Faculty of Medicine, University of Constantine-3, Algeria \\ ${ }^{4}$ Laboratory of Expertise and Analysis of Sport Performance, University of Constantine 2, Algeria \\ ${ }^{5}$ Clinique Privé D'allergologie Constantine, Algeria \\ ${ }^{6}$ Laboratory of Cellular and Molecular Biology, Faculty of the Sciences, Constantine1 University, Algeria \\ ${ }^{7}$ Oral Ecology Research Group, Faculty of Dentistry, Laval University, Quebec, QC, Canada
}

Article history

Received: 20-06-2017

Revised: 28-09-2017

Accepted: 31-10-2017

Corresponding Author:

Mahmoud Rouabhia

Oral Ecology Research Group,

Faculty of Dentistry, Laval

University, Quebec, QC,

Canada

E-mail: mahmoud.rouabhia@fmd.ulaval.ca

\begin{abstract}
Atopy is characterized by the production of a high level of $\operatorname{IgE}$ in response to common allergens. We examined the RsaI-in2 polymorphism of the $F c \varepsilon R I-\beta$ gene and its association with atopic asthma and comorbidity. The study population included 77 atopic asthmatics and 77 non-atopic, nonallergic and non-asthmatic controls. Atopic asthma was confirmed by the skin prick test and by $\operatorname{IgE}$ and interleukin IL-4 levels. RsaI-in2 polymorphism was determined by RFLP-PCR using the RsaI enzyme. A significant correlation was found between genotype BB and sensitization to house dust mites in the asthmatic subjects $(p=0.000)$. Results also reveal significant allele sharing in the subjects affected by eczema $(p=0.000)$ and allergic rhinitis $(p=0.01)$ during childhood. Furthermore, the subjects with heterozygous $\mathrm{AB}$ and homozygous $\mathrm{BB}$ genotypes displayed significant $\mathrm{IgE}$ levels $>1000 \mathrm{UI} \mathrm{mL}^{-1}$. IL-4 levels were also $>1000 \mathrm{pmol} / \mathrm{ml}$ for RsaI-in2 polymorphism genotype BB. Our findings show a strong association between genotype $\mathrm{BB}$ and the incidence of eczema and allergic rhinitis in childhood as well as increased IgE and IL-4 levels.
\end{abstract}

Keywords: Allergy, Asthma, FceRI- $\beta$, IgE, IL-4, RsaI-in2 Polymorphism

\section{Introduction}

Asthma is a major public health problem affecting millions people worldwide (Report TGA, 2014). The prevalence and the impact of asthma are on the rise particularly in polluted regions. With a projected surge in the world's urban population, it is estimated that number asthmatic people will significantly increase by 2025 (Asamoah et al., 2017). Asthma is therefore set to become one of the world's most prevalent chronic diseases (Licari et al., 2017).

Asthma occurs at all ages (Baxter et al., 2017; Terry et al., 2017). The elderly population ( $>65$ years of age) account for $13 \%$ of the U.S. population (Baxter et al., 2017; Terry et al., 2017). This age group will account for $25 \%$ of the population by 2050 (Hanania et al., 2011). Asthma prevalence in the elderly patient is difficult to determine because of underdiagnosis due to patient underreporting of asthma symptoms or of misdiagnosis as Chronic Obstructive Pulmonary Disease (COPD) (Enright et al., 1999). It has been reported that the annual prevalence of self-reported asthma in individuals who are $>65$ years old is $6.8 \%$ (Moorman et al., 2007). There is a known link between the early presence of atopy and the later development of asthma (Fiuza et al., 2017).

The term atopy, originally used to describe such allergic conditions as asthma, allergic rhinitis and eczema, is a key predisposing factor in the development of asthma, which has a genetic background and is highly modulated by external environmental factors (Bantz et al., 2014; Fiuza et al., 2017). Atopy is defined as an inherited tendency toward an immune response that is characterized by high
Science

Publications 
concentrations of $\operatorname{IgE}$ against common aeroallergens in a genetically predisposed person (de Guia and Ramos, 2010; Bijanzadeh et al., 2011).

IgE activates different cells including mast cells, basophils, eosinophils and Langerhans cells through FceRI, the high-affinity IgE receptor involved in the pathogenesis of aeroallergens (Hong et al., 2015; Lee and Yu, 2011; Suurmond et al., 2016). Cell activation causes an inflammatory reaction in the airways, nasal cavity and the integument which clinically manifest symptoms of the atopic triad (asthma, eczema and allergic rhinitis) (de Guia and Ramos, 2010). It has been reported that atopy and asthma are linked to the 11q12-13 chromosome region and it has also been shown that the transmission of the chromosome 11q locus is detectable only through the maternal line (Mersha, 2015).

The FcERI- $\beta$ gene is composed of seven exons and six introns spanning approximately $11 \mathrm{~kb}$ (Pinto et al., 2008; Terada et al., 2016). It was revealed that coding and non-coding variants of $F c \varepsilon R I-\beta$ gene is associated with an increased risk of atopic status (KorzyckaZaborowska et al., 2014). The restriction site enzyme is created by the substitution of Cytosine (C) nucleotide by Adenine (A) nucleotide at nucleotide position 1660 of the Fc\&RI- $\beta$ gene, namely, 1651 TAACTGGGT C (A) CTTTT 1665 (Shirakawa et al., 1994). This non-coding variant was selected for atopy linkage studies based on the presence of the $F_{c} \varepsilon R I-\beta$ gene and the availability of many polymorphic markers (Hizawa et al., 2006). This may provide additional areas for genetic research because the presence of polymorphism could cause a splicing error, the creation of an active site for $\operatorname{IgE}$, or the creation of a stop codon, which may all contribute to altering the $\operatorname{IgE}$ receptor (Hizawa et al., 2006). It is possible that mutations in genes that code for the $\operatorname{IgE}$ receptor may be responsible for the development of early hypersensitivity reactions in atopic persons by increasing the production of IL4 and activating inflammatory cells (Rabe et al., 2011). The $\beta$-chain of FceRI stabilizes the receptor's surface expression and acts as an amplifying element (A allele is represented by the letter $\mathrm{B}$ and $\mathrm{C}$ allele by the letter $\mathrm{A}$ in the manuscript, as defined in the literature) (Castro et al., 1998).

The aim of this immunogenetic study was to investigate the association of RsaI-in2 polymorphism in the FceRI gene $\beta$-subunit with atopic asthma, allergic rhinitis and eczema in a population of Eastern Algeria. Also investigated was the genetic association between intron 2 FceRI- $\beta$ polymorphism and the phenotypic traits, as well as the clinical and biological components of atopic asthma.

\section{Participants and Methods}

\section{Participants}

Our case-control study included 77 patients with atopic asthma (37 men and 40 women, aged $32.13 \pm 17.79$ years) and 77 healthy controls (54 men and 23 women, aged $35.94 \pm 16.63$ years). Subjects were recruited from the Constantine University hospital center between January 2011 and March 2014. Written consent was obtained from each participant prior to their enrollment in the study. The healthy controls were non-smokers, with no symptoms of atopy, as defined by negative skin prick tests for common aeroallergens, a blood $\mathrm{IgE}$ concentration lower than $100 \mathrm{IU} / \mathrm{mL}^{-1}$ and the absence of pulmonary disease or any other comorbid diseases. Atopic asthma patients with any other history of respiratory illness, such as chronic obstructive pulmonary disease, tuberculosis, pneumonia, or bronchitis, were excluded from this study. Also excluded were patients with any other comorbid illnesses, such as gastroesophageal reflux, polyps, obesity, pregnancy, a smoking history, or one of the following diseases: immune deficiency, infection, parasitic infestation, malignancy, or systemic disease, which increase the IgE levels.

The atopic asthmatic participants were subjected to clinical investigations to confirm the asthma. The inclusion criteria were as follows: (i) Asthma confirmed for at least two years, as defined by the American Thoracic Society criteria (Standards for the diagnosis and care of patients with Chronic Obstructive Pulmonary Disease (COPD) and asthma; this official statement of the American Thoracic Society was adopted by the ATS Board of Directors, November 1986-1987); (ii) The absence of corticosteroid therapy in the previous four weeks; and (iii) a positive skin prick test with at least two aeroallergens.

It has been reported that some asthmatics show a personal history of eczema and allergic rhinitis at a young age. Eczema diagnosis and monitoring were thus performed by each subject's doctor according to the Hanifin and Rajka diagnostic criteria (Hiletework, 2009). The SCORAD (SCORing Atopic Dermatitis) (Gelmetti et al., 2012) was also used to assess the extent and severity of the eczema. The allergic rhinitis diagnosis and management were determined by the treating physician according to Allergic Rhinitis and its Impact on Asthma (ARIA recommendation) (Brożek et al., 2010), the respiratory infections data were retrieved from each patient's medical chart. Of note is that these subjects developed eczema and allergic rhinitis during the first five years of their lives. 


\section{Clinical Examinations}

A clinical examination of the patients was performed by two independent physicians and included lung auscultation (morphology, expansion), a survey related to allergic rhinitis and eczema at a young age and a lung function test to investigate asthma and assess the level of asthma control during the previous four weeks, according to the American Thoracic Society and guideline criteria (Bateman et al., 2008). The evaluation criteria were as follows: Daytime and nocturnal symptoms, use of rescue medications (short-acting bronchodilators), activity limitations, frequency of exacerbations and lung function parameters (Bousquet and Busse, 2010). Each participant underwent Pulmonary Function Tests (PFTs) (Zan 100, Megretâte GmbH, Oberthulba, Germany) according to the American Thoracic Society/European Respiratory Society (ATS/ERS) (Miller et al., 2005). Detection of the obstructive syndrome was confirmed by the Forced expiratory volume in 1 (FEV1)/Forced Volume vital Capacity (FVC) [FEV1/FVC] ratio or Tiffeneau index, FEV1/VC $\leq$ Low limit normal (LIN) or FEV1/FVC $<0.7$ (Bateman et al., 2008). Suspected asthmatics were asked to undergo a reversibility test by administering four puffs of a beta-2-mimetic shortacting medication (Ventolin at $400 \mu \mathrm{g}$ ). Values of $12 \% \mathrm{FEV} 1$ and $200 \mathrm{~mL}^{-1}$ of improvement of FCV confirmed the asthmatic status.

Atopic status was confirmed by at least two positive skin prick tests using a panel of 15 specific aeroallergens (100 IR $\mathrm{mL}^{-1}$, Laboratoires Stallergénes ${ }^{\circledR}$, Paris, France). A positive result was determined as a papule diameter greater than $4 \mathrm{~mm}$ after $15-20 \mathrm{~min}$ of aeroallergen administration using a standardized procedure (Heinzerling et al., 2013), which was further confirmed by IgE and IL-4 measurements.

\section{Survey}

The survey pertained to the past and current respiratory health of each participant. It included the age, severity of asthma and atopy, childhood respiratory infections with hospitallization, family history of asthma, atopy and other respiratory diseases, history of allergic reactions or asthma symptoms while exposed to specific aeroallergens, drugs, parental smoking, consanguineous marriages within three previous generations, major asthma symptoms such as wheezing, coughing and chest tightness, exacerbation frequency, sports activity in relation to asthma and use of asthma/allergic medications.

\section{Blood Sample Collection}

Approximately 10-ml samples of venous blood were obtained from the arm of each participant to measure IgE and IL-4 levels. An additional $10 \mathrm{~mL}^{-1}$ of blood was collected using EDTA-coated vials for leukocyte isolation and DNA extraction.
Determination of $I L-4$ and $\operatorname{IgE}$ Levels in the Collected Blood Serum

The Quantia IgE immunoturbidimetric assay (Biokit, S.A., Barcelona, Spain) was used to measure the level of IgE in the collected blood serum. The level of IgE confirming the atopic status is reported to be in the range of 100 to 400 (de Guia and Ramos, 2010). In the present study, we considered IgE overproduction when the measured concentration was equal or over $300 \mathrm{IU} \mathrm{mL} \mathrm{m}^{-1}$, as previously reported (Hizawa et al., 1995). An immunosorbent assay (ELISA) kit (DRG International, Inc., Springfield, MA, USA) was used to measure IL-4 levels using a standard curve derived from known amounts of the relevant cytokine with absorbance readings at $450 \mathrm{~nm}$ by means of a spectrophotometer (MindrayMR-96A microplate reader, Shenzhen, China). The minimum detection level for the cytokines was $<2 \mathrm{pg} \mathrm{mL}^{-1}$.

\section{Genotyping of Intron 2- FcERI- $\beta$ Polymorphism}

Leukocytes were isolated from each blood sample and genomic DNA was extracted by means of a saltingout method (Miller et al., 1988). DNA levels were first quantified by spectrophotometry and then subjected to $2 \%$ agarose gel electrophoresis analyses for quality control prior to investigating the RsaI-in2 polymorphism, which was detected using the Polymerase Chain Reaction (PCR) and a subsequent restriction analysis using the RsaI enzyme. PCR was performed with $200 \mathrm{ng}$ of genomic DNA in a final volume of $20 \mu \mathrm{l}$. The PCR mixture contained 1X Gold Taq Taq buffer, $25 \mathrm{mM}$ of $\mathrm{MgCl} 2,0.2 \mathrm{mM}$ of dNTPs (Invitrogen, Carlsbad, CA, USA), $10 \mu \mathrm{M}$ of each of the following primers (forward: 5' GAATGGCCAACAGGAGTGAAGGAT-3'; reverse: 5'-CAAGTACAGAGCAGACAACT-3') and $1.25 \mathrm{U}$ of Got Taq ${ }^{\circledR}$ Hot start polymerase (Promega, Madison, WI, USA). The PCR thermocycling conditions consisted of $94^{\circ} \mathrm{C}$ for $5 \mathrm{~min}$, followed by 34 cycles of $94^{\circ} \mathrm{C}$ for 1 $\min , 59^{\circ} \mathrm{C}$ for $1 \mathrm{~min}$ and $72^{\circ} \mathrm{C}$ for $2 \mathrm{~min}$. Restriction enzyme digestion was carried out by adding $1 \mathrm{X} R$ buffer, $0.1 \mathrm{mg} \mathrm{mL}^{-1}$ of bovine serum albumin and $2 \mathrm{U}$ of RsaI restriction enzyme (New England Biolabs, Ipswich, MA, USA) to a PCR tube containing $10 \mu \mathrm{L}^{-1}$ of PCR products. The mixture was then spun down and incubated at $37^{\circ} \mathrm{C}$ for $16 \mathrm{~h}$, after which time the fragments were separated by electrophoresis on $3 \%$ agarose gel and subsequently visualized with ethidium bromide under UV light. The assay yielded a single 749-bp band for the BB genotype, two bands of 428$\mathrm{pb}$ and 321-pb for the AA homozygote and three bands of 749-pb, 428-pb and 321-pb for the AB heterozygote (Fig. 1). 


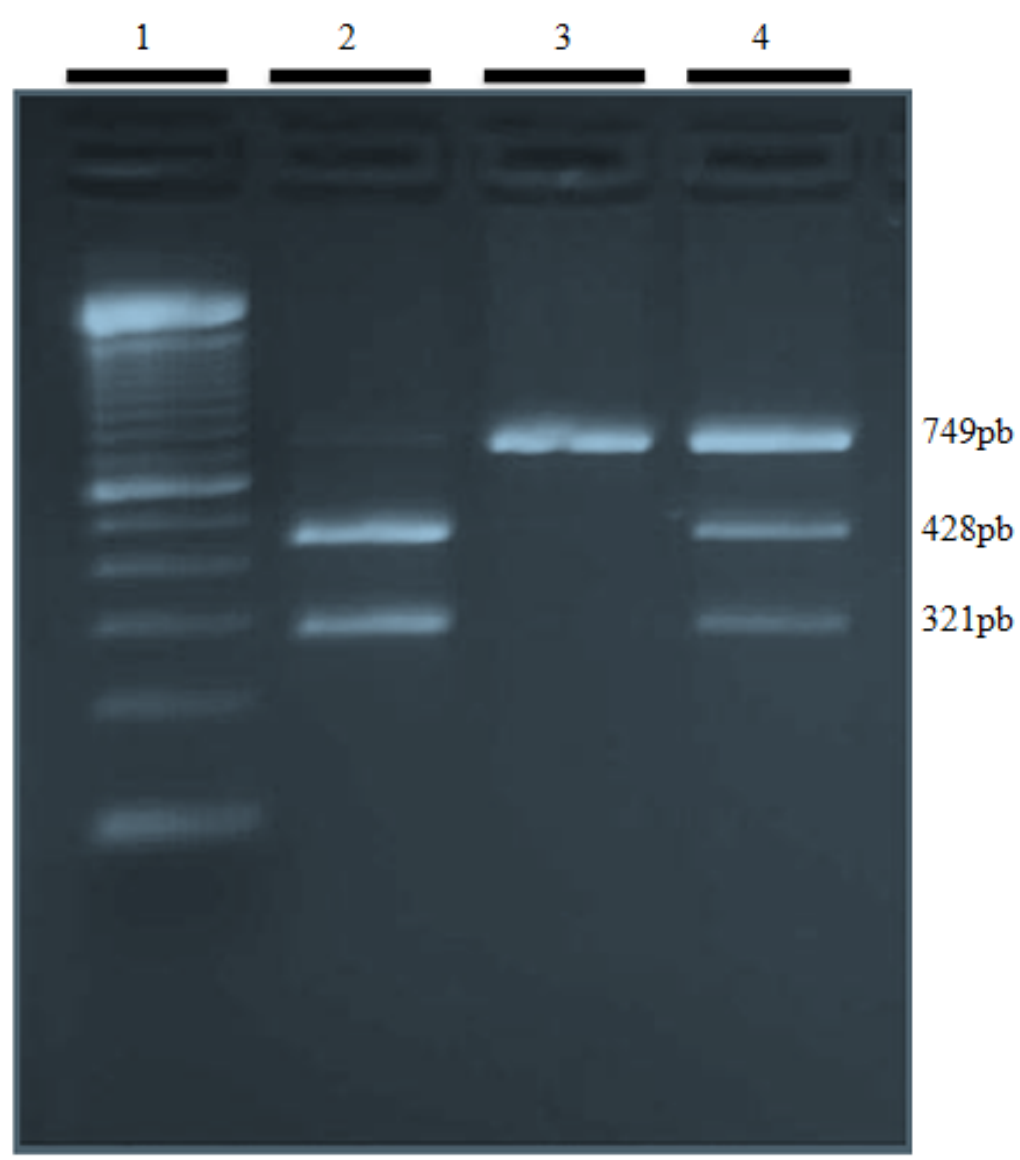

Fig. 1: Agarose gel (3\%) electrophoresis stained with ethidiumbromide, showing genotypes observed by restriction enzyme analysis after digestion with Rsal. Lane 1: 100 bp DNA size markers; lane 2: A/A; lane 3: B/B; lane 4: A/B

\section{Statistical Analysis}

The data were analyzed using SPSS version 20 software. The continuous variables were expressed as means \pm SD. Comparisons between the means were performed using the Student $t$-test and for the quantitative variables, the ANOVA test. The significance level of the statistical tests was set at $p<0.05$. The chisquare test was used to determine differences in genotype/allele frequency and deviation from the HardyWeinberg Equilibrium (HWE) and in the comparisons between groups, with the statistical significance determined as $\mathrm{p}<0.001$.

\section{Results}

Table 1 presents detailed characteristics of the asthmatic and non-asthmatic subjects, showing no association between the size $(p=0.070)$ and weight $(p=$ 0.411 ) of the subjects and the development of atopic asthma. However, the biological parameters reveal that the subjects with atopic asthma displayed significantly $(p<0.05)$ higher levels of $\operatorname{IgE}\left(637.26 \pm 247.88 \mathrm{UI} \mathrm{mL}^{-1}\right)$ compared to that recorded by the healthy control subjects $\left(32.27 \pm 15.63 \mathrm{UI} \mathrm{mL}^{-1}\right)$. The same observation was made with the levels of IL-4, with the asthmatics measuring $567.74 \pm 246.76 \mathrm{pmol} / \mathrm{ml}$ of IL-4 and the healthy controls $26.57 \pm 8.99 \mathrm{pmol} / \mathrm{ml}$. Our data also shows that the FEV1 was significantly lower in the asthmatic subjects than in the healthy controls $(p=0.0000)$.

We then proceeded to examine the association of rhinitis and eczema with the development of atopic asthma during the life cycle of our subjects. Our results showed a highly significant difference between the asthmatic and control subjects, with a $59.74 \%$ of patients having eczema and $58.44 \%$ suffering from allergic rhinitis as compared to the controls (Table 1).

Genotype distributions in the asthmatic and control groups were tested for Hardy-Weinberg equilibrium. The chi-square test was used to analyze the observed and expected frequencies in each group. Our findings show that the distribution of the genotype and allele frequencies of RsaI-in2 polymorphism in both the asthmatic patients 
and the healthy controls was in Hardy-Weinberg equilibrium $(\mathrm{p}>0.001)$ with the following expressed values: $\left(X_{2}=1.42, \mathrm{p}=0.23\right)$ for the asthmatic subjects and $\left(X_{2}=5.09, \mathrm{p}=0.02\right)$ for the controls.

Our investigation of RsaI-in2 polymorphism within the intron 2 of the FceRI $\beta$-chain revealed no significant difference in genotype frequency between the subjects with atopic asthma and the normal control subjects $(p>0.05)$. The values were $28.4 \%$ among patients' vs $23.4 \%$ in control for genotype AA; $55.8 \%$ among patients' vs $62.3 \%$ in control for heterozygous genotype $\mathrm{AB}$ and $15.6 \%$ among patients' Vs $14.3 \%$ in control for genotype BB.

For the genotypic frequencies no significant association was established between the RsaI-in2 polymorphism genotypes and atopic asthma when comparing AA Vs BB (OR, 0.89; IC 95\% 0.31-2.49; $\mathrm{p}=$ 0.82), BB Vs AB (OR, 1.21; IC 95\% 0.48-3.04; p = 0.67 ), AA Vs AB+BB (OR, 0.76 ; IC 95\% 0.37-1.57; p $=0.46)$ or $\mathrm{AA}+\mathrm{AB}$ Vs BB (OR, 1.10; IC 95\% 0.45-2.68; $\mathrm{p}=0.82)$. Similarly, no statistically significant difference in allele frequency was found when comparing the asthmatic and control subjects, with the following allelic distribution: (OR, 1.08; IC 95\% $0.69-1.69 ; \mathrm{p}=0.73$ ) for a allele and (OR, 0.92; IC $95 \% 0.58-1.44 ; \mathrm{p}=0.73$ ) for B allele (Table 2).

These results led us to hypothesize that this polymorphism could be associated with atopy regarding allergies (mono/poly sensitization), eczema and allergic rhinitis in asthmatic subjects. To confirm these assumptions, we investigated whether mutant allele $\mathrm{B}$ in asthmatic patients induced an exaggerated immune response to the most common aeroallergens, such as House Dust Mites (HDM) and Alternaria. Figure 2 shows a significant association between the BB genotype of RsaI-in2 polymorphism and sensitization to HDM $(p=0.04)$ in the sensitized and non-sensitized subjects. However, there was no significant difference between the distribution of the $\mathrm{AA}, \mathrm{AB}$ and $\mathrm{BB}$ genotypes of RsaI-in 2 polymorphism and sensitization to Alternaria in these two groups ( $>00.05)$ (Fig. 2 and Table of Figure 2).

Subsequently, we explored the phenotypic traits and biological components of atopy, as highlighted in Table 3. Results show no significant difference between the RsaI-in2 polymorphism of $F c \varepsilon R I-\beta$ and papule diameter in the skin prick test $(p=0.68)$ in both groups of our study, although a highly significant $(p=0.000)$ association was found between RsaI-in2 polymorphism and IgE levels. Indeed, we showed a significant $(p=0.000)$ association between the RsaIin2 polymorphism and the increase of IL-4 levels in asthmatic patients. Conversely, no significant difference in IgE and IL-4 levels was observed between genotypes $\mathrm{AA}, \mathrm{BB}$, or $\mathrm{BB}(\mathrm{p}>0.05)$ in the healthy control subjects.

Using genotype AA as a reference, we observed a significant difference between genotypes $\mathrm{AB}$ and $\mathrm{BB}$ and the occurrence of eczema and allergic rhinitis in childhood. Our results demonstrate that the asthmatics with genotypes $\mathrm{AB}$ or $\mathrm{BB}$ were more prone to developing eczema $(\mathrm{p}<0.05)$ and allergic rhinitis $(p<0.05)$ at a younger age than were those with genotype AA (Fig. 3 and table

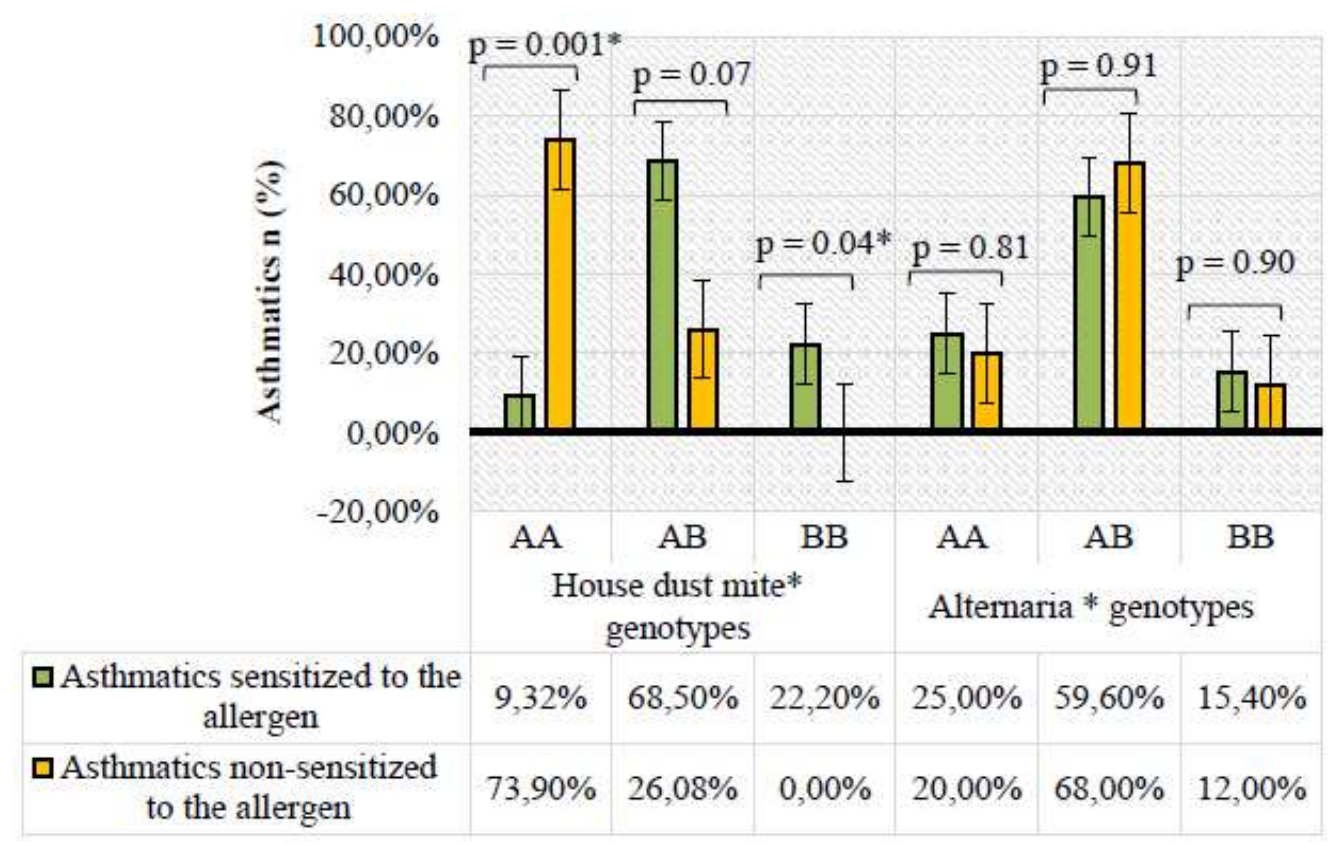

Fig. 2: Distribution of RsaI-in2 polymorphism genotypes according to symptoms associated with asthma in asthmatic patients. $(*)$ refers to significant value $\mathrm{p} \leq 0.05$ by chi-square statistical analysis 
Table 1: Baseline, physiological and biological characteristics of the study population

\begin{tabular}{llll}
\hline Characteristics & Controls $(\mathrm{n}=77)$ & Asthmatics $(\mathrm{n}=77)$ & P value \\
\hline Sizes $(\mathrm{cm}) \uparrow$ & $1.66 \pm 0.16$ & $1.62 \pm 0.15$ & 0.070 \\
Weights $(\mathrm{kg}) \uparrow$ & $69.12 \pm 19.72$ & $67.31 \pm 24.19$ & 0,411 \\
Baseline FEV1 $\uparrow$ & $86.13 \pm 8.30$ & $77 \pm 10$ & $0.0000^{* *}$ \\
Measured IgE, UI/ml $\uparrow$ & $32.27 \pm 15.63$ & $637.26 \pm 247.88$ & $0.0000^{* *}$ \\
Measured IL4, pmol/ml $\uparrow$ & $26.57 \pm 8.99$ & $567.74 \pm 246.76$ & $0.0000^{* *}$ \\
Allergic rhinitis & 0 & $45(58.44 \%)$ & -------- \\
Eczema & 0 & $46(59.74 \%)$ & $-----{ }^{---}$ \\
\hline
\end{tabular}

$\uparrow$ Data are means \pm Standard Deviations (SD); (n) refers to the number of subjects; $\left(^{* *}\right)$ refers to $\mathrm{p}<0.01$. FEV1 refers to forced expiratory volume during $1 \mathrm{sec}$. The $\mathrm{P}$ value was assessed via one-way ANOVA

Table 2: Determination of the genetic effects of the RsaI-in2 polymorphism on asthma

\begin{tabular}{llllll}
\hline & & Controls & Asthmatics & OR (95\% CI) & P-value \\
\hline Alleles & A allele n (\%) & $84(54.55 \%)$ & $87(56.49 \%)$ & $1.08(0.69-1.69)$ & 0.73 \\
& B allele n (\%) & $70(45.45 \%)$ & $67(43.51 \%)$ & $0.92(0.58-1.44)$ & 0.73 \\
Genotypes & $18(23.4 \%)$ vs. 11(14.3\%) & $22(28.6 \%)$ vs. $12(15.6 \%)$ & $0.89(0.31-2.49)$ & 0.82 \\
& AA vs. BB n (\%) & $18(23.4 \%)$ vs. 48(62.3\%) & $22(28.6 \%)$ vs. 43(55.8\%) & $1.36(0.64-2.87)$ & 0.41 \\
& AA vs. AB n (\%) & $11(14.3 \%)$ vs. 48(62.3\%) & $12(15.6 \%)$ vs. 43(55.8\%) & $1.21(0.48-3.04)$ & 0.67 \\
& BB vs. AB n (\%) & $18(23.4 \%)$ vs. 59(76.6\%) & $22(28.6 \%)$ vs. 55(71.4\%) & $0.76(0.37-1.57)$ & 0.46 \\
& AA vs. AB+BB & $11(14.3 \%)$ vs. 66(85.7\%) & $12(15.6 \%)$ vs. 65 (84.4\%) & $1.10(0.45-2.68)$ & 0.82 \\
\hline
\end{tabular}

(*) refers to significant value $\mathrm{p}<0.05$; (n) refers to the number of subjects

Table 3: Associations between the RsaI-in 2 polymorphism, skin prick test and serological measurements linked to atopy

\begin{tabular}{llllll}
\hline Diameter of the papule $(\mathrm{mm})$ & AA & $18(23.4 \%)$ & 0 & $22(28.6 \%)$ & $5.86 \pm 1.59$ \\
\hline & AB & $48(62.3 \%)$ & 0 & $43(55.8 \%)$ & $6.05 \pm 1.16$ \\
P value & BB & $11(14.3 \%)$ & 0 & $12(15.6 \%)$ & $6.33 \pm 1.44$ \\
Serum IgE $(\mathrm{IU} / \mathrm{ml})$ & & $77(100 \%)$ & $77(100 \%)$ & 0.68 & \\
& AA & $18(23.4 \%)$ & $33.64 \pm 16.05$ & $22(28.6 \%)$ & $380.6 \pm 37.66$ \\
P value & AB & $48(62.3 \%)$ & $32.39 \pm 15.27$ & $43(55.8 \%)$ & $447.4 \pm 187.9$ \\
Serum concentrations IL 4 (pmol/ml) & BB & $11(14.3 \%)$ & $28.45 \pm 17.35$ & $12(15.6 \%)$ & $>1000$ \\
& AA & $77(100 \%)$ & 0,53 & $77(100 \%)$ & $0.0000^{*}$ \\
& AB & $48(23.4 \%)$ & $31.5 \pm 8.70$ & $17(21.2 \%)$ & $348.36 \pm 48.19$ \\
P value & BB & $11(14.3 \%)$ & $27.16 \pm 7.91$ & $44(55 \%)$ & $664.32 \pm 48.19$ \\
\hline
\end{tabular}

(n) Refers to the number of subjects (percentage. \%); $(\mathrm{x} \pm \sigma)$ are means \pm Standard Deviations $(\mathrm{SD}) ;(*)$ refers to significant value at $\mathrm{p} \leq 0.05$ calculated by Kruskal Wallis test

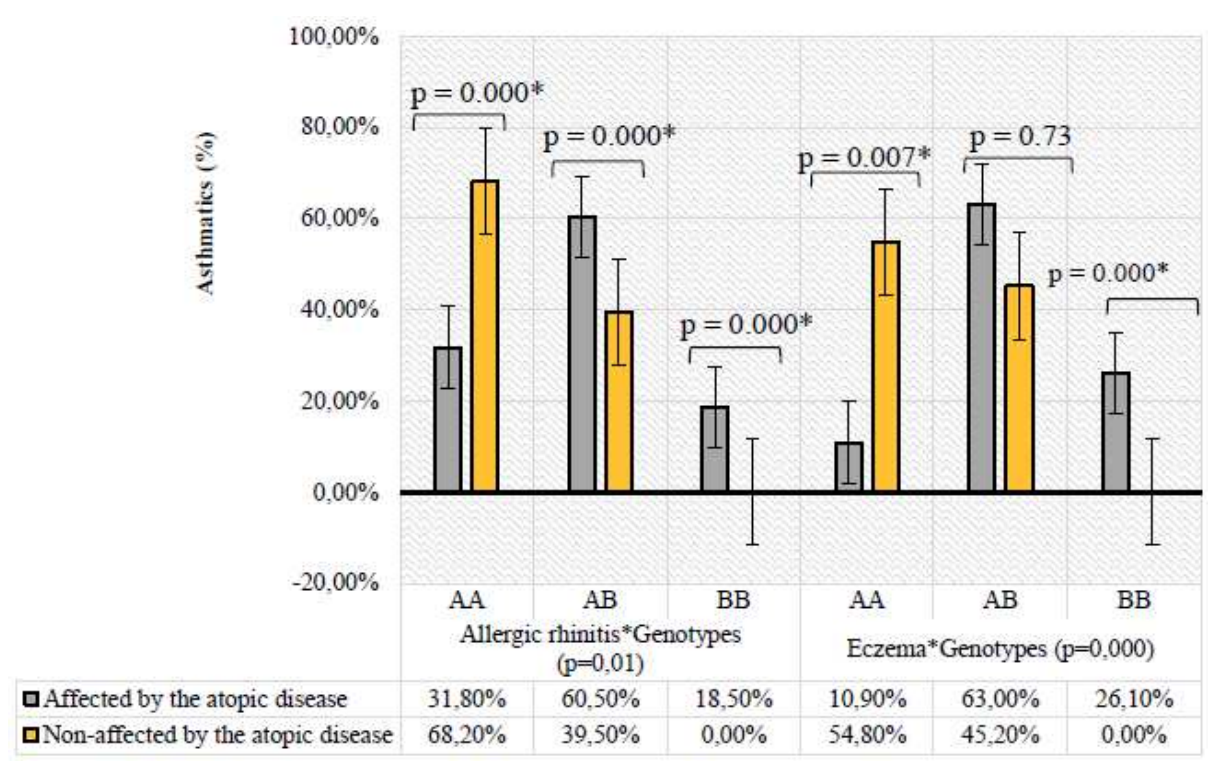

Fig. 3: Association of Rsa1-int2 polymorphism with allergic rhinitis and eczema in asthmatic patients. $(*)$ refers to significant value $\mathrm{p} \leq 0.05$ using chi-square 
Table of Figure 2: Distribution of RsaI-in2 polymorphism genotypes according to symptoms associated with asthma in asthmatic patients. $(*)$ refers to significant value $\mathrm{p} \leq 0.05$ by chi-square statistical analysis

\begin{tabular}{|c|c|c|c|c|}
\hline & & \multicolumn{3}{|l|}{ Genotypes } \\
\hline & & AA & $\mathrm{AB}$ & $\mathrm{BB}$ \\
\hline \multirow[t]{2}{*}{ House dust mite } & Asthmatics sensitized to the allergen & $(9.32 \%) 5$ & $(68.50 \%) 37$ & $(22.20 \%) 12$ \\
\hline & Asthmatics non-sensitized to the allergen & $(73.90 \%) 17$ & $(26.08 \%) 6$ & $(0.00 \%) 0$ \\
\hline$P$ values & $0.001 *$ & 0.07 & $0.04 *$ & \\
\hline \multirow[t]{2}{*}{ Alternaria } & Asthmatics sensitized to the allergen & $(25.00 \%) 10$ & $(59.60 \%) 24$ & $(15.4 \%) 6$ \\
\hline & Asthmatics non-sensitized to the allergen & $(20.00 \%) 7$ & $(68.00 \%) 25$ & $(12.00 \%) 5$ \\
\hline$P$ values & 0.81 & 0.91 & 0.9 & \\
\hline
\end{tabular}

Table of Figure 3: Association of RsaI-in2 polymorphism with allergic rhinitis and eczema in asthmatic patients. $(*)$ refers to significant value $\mathrm{p} \leq 0.05$ by chi-square statistical analysis

\begin{tabular}{|c|c|c|c|c|}
\hline & & \multicolumn{3}{|l|}{ Genotypes } \\
\hline & & AA & $\mathrm{AB}$ & $\mathrm{BB}$ \\
\hline \multirow[t]{2}{*}{ Allergic rhinitis } & Affected by the atopic disease & $(31.80 \%) 7$ & $(60.50 \%) 26$ & $(18.50 \%) 12$ \\
\hline & Non-affected by the atopic disease & $(68.20 \%) 15$ & $(39.50 \%) 17$ & $(0.00 \%) 0$ \\
\hline$P$ values & & $0.000^{*}$ & $0.000 *$ & $0.000 *$ \\
\hline \multirow[t]{2}{*}{ Eczema } & Affected by the atopic disease & $(10.90 \%) 2$ & $(63.00 \%) 27$ & $(26.10 \%) 17$ \\
\hline & Non-affected by the atopic disease & $(54.80 \%) 12$ & $(45.20 \%) 19$ & $(0.00 \%) 5$ \\
\hline$P$ values & & $0.007 *$ & 0.73 & $0.000 *$ \\
\hline
\end{tabular}

\section{Discussion}

We compared atopic asthma prevalence in males and females in the same age range. No significant difference was found between girls and boys under ten years of age, while a significantly increased incidence of atopic asthma was found among teenage girls and adult women, as compared to males. This observation is in agreement with other findings (Choi, 2011). This research group reported that asthma symptoms show cyclic changes depending on female hormone levels in many women of child-bearing age, the use of contraceptives in women may specifically help treat such perimenstrual asthma and severe asthma. In addition, recent studies have shown that the probability of developing atopic asthma is approximately $10.5 \%$ higher in women than in men, which suggests the potential effect of female sex hormones on immune function, thereby inducing increased IL-4 and IgE production (Vasiadi et al., 2006; Choi, 2011). Differences in asthma incidence during menopause period lend further support to the idea that sex-related differences may be influenced by alterations in levels of the female sex hormones. Indeed, the overall incidence of asthma in women decreases after menopause (Fuseini and Newcomb, 2017; Baldaçara and Silva, 2017). This was supported by studies showing that the use of postmenopausal hormone therapy was associated with an increased rate of newly diagnosed asthma in menopausal women (Bonnelykke et al., 2015; Dratva, 2010). One suggested mechanism was the possible local effect of sex hormones on resident lung cells (Melgert et al., 2007; Kynyk et al., 2011).
A personal history of allergic rhinitis and eczema is another major factor possibly involved in the occurrence of atopic asthma. In our study population, $58.44 \%$ of the asthmatics had allergic rhinitis. These results are similar to those of Shaaban et al. (2008) who viewed allergic rhinitis as an important risk factor for atopic asthma. These authors also showed that subjects with allergic rhinitis were 3.5 times more at risk of developing asthma than were unaffected asthmatics. In another study, $41.5 \%$ of subjects with allergic rhinitis in childhood or adolescence were shown to be 3.8 times more at risk of developing atopic asthma (Rochat et al., 2010). In our study population, $59.74 \%$ of the asthmatics had had eczema at a young age. This finding may support the suggestion that asthmatics who have had eczema before the age of five have a higher risk of developing a respiratory allergy (Spergel, 2010).

Considering the previous association of asthma with a geneticmarker located on chromosome 11 (Rava et al., 2017), we investigated the potential link between RsaIin2 polymorphism and asthma. In comparing the asthmatic and control subjects, results show nonsignificant differences in the distribution of the two alleles of RsaI-in2 polymorphism (A and B) and three genotypes (AA, AB and $\mathrm{BB}$ ). These data thus suggest no association between RsaI-in2 polymorphism and atopic asthma, as previously reported (Castro et al., 1998; Fukao et al., 1996).

Interestingly, we demonstrated that genotypes $\mathrm{AB}$ and $\mathrm{BB}$ of the RsaI-in2 polymorphism gene were significantly associated with House Dust Mite (HDM) allergy, which was present in $59.74 \%$ of the households in the groups under study. These data support those 
reported by Young et al. (1992). This group reported that the predisposition to atopy is primarily under genetic control at chromosome llq. However, the specific IgE response to HDM in the atopic children is, at least in part, linked to the magnitude of allergen exposure. They also suggest that other factors such as HLA loci may influence the response to HDM.

It is well known that RsaI-in2 polymorphism in the FceR1 $\beta$ gene alters mast cell sensitivity through mediator release, which plays an active role in vascular permeability, smooth muscle constriction, mucus secretion and leukocyte chemo-attraction (Casale and Marom, 1983), which in turns increases the severity of atopic asthma. We confirm such a link between mediators, mast cell activation and asthma, as our findings show a high level of IgE and IL-4, suggesting a link between RsaI-in2 polymorphism, atopy and elevated IL-4 and IgE levels, as previously reported (van Hage-Hamsten et al., 2002; Chan et al., 2008).

Furthermore, our results show a significant positive association between RsaI-in2 polymorphism and eczema, suggesting that genotypes $\mathrm{AB}$ and $\mathrm{BB}$ could be factors contributing to the occurrence of eczema at a young age. These findings are in agreement with those of other studies (Shirakawa et al., 1994; van Hage-Hamsten et al., 2002). Shirakawa et al. (1994) have identified a common variant of Fc epsilon RI- $\beta$, lle181Leu within the 4th transmembrane domain. They showed that the Leu181 had significant association with positive $\operatorname{IgE}$ responses. Amongst 60 unrelated nuclear families with allergic asthmatic probands, Leu181 is identified in $10(17 \%)$, is maternally inherited in each and shows a strong association with atopy. They conclude that Fc epsilon RI-beta, subject to maternal modification, may be the atopy-causing locus on chromosome 11q.

We also demonstrated that genotypes $\mathrm{AB}$ and $\mathrm{BB}$ were more frequent in the asthmatic group who had had allergic rhinitis in childhood than in the group of asthmatics who had never had allergic rhinitis, which is in agreement with other findings (Korzycka-Zaborowska et al., 2004).

Our results indicate no association between genotypes $\mathrm{AA}, \mathrm{AB}$ and $\mathrm{BB}$ of RsaI-in2 polymorphism and the largest papule diameter in the skin prick test. This can be attributed to the onset of an inflammatory reaction following aeroallergen administration, which was a common point among all of our subjects. We thus performed IgE and IL-4 testing to present quantitative results. Our findings demonstrate a close and highly significant relationship between RsaI-in2 polymorphism, atopy and elevated serum levels of IL-4, which are known to cause a switch to $\operatorname{IgE}$ production by differentiating B cells leading to high levels of IgE. Our study is supportive to van Hage-Hamsten et al. (2002) study showing that Atopy was found to be associated with the RsaI-ex7 AB-genotype ( $\mathrm{OR}=1.9 ; \mathrm{P}=0.04)$. The RsaI-ex7 B allele had a significant influence on IgE responses to pollens and dust mites $(\mathrm{OR}=5.5 ; \mathrm{P}=0.03$ and $\mathrm{OR}=5.2 ; \mathrm{P}=0.049$, respectively). They also reported that the influence of $\mathrm{B}$ allele was stronger when the association towards single dust mite species (Lepidoglyphus destructor) was estimated (OR $=7.1, \mathrm{P}=$ 0.03 ) and the association increased even more when the major allergen of L. destructor (rLep d 2) was analyzed $(\mathrm{OR}=11.2, \mathrm{p}=0.02)$. Thus, there is an association between RsaI-in2 polymorphism, atopy and elevated serum levels of IL-4 in our study population from the city of Constantine, Algeria, Further studies are required throughout Algeria to confirm this correlation.

\section{Conclusion}

In this study, we were able to show that asthma was more prevalent in women than in men in adolescence and adulthood, in the city of Constantine in eastern Algeria. Subjects who suffered from allergic rhinitis and eczema in early childhood were also more susceptible to the subsequent development of atopic asthma.

On the other hand, our results demonstrate that the presence of RsaI-in2 polymorphism genotype $\mathrm{BB}$ in the second intron of the Fc\&RI- $\beta$ gene induced elevated IgE and IL-4 secretion as well as a hyper sensitization to house dust mites. Genotype BB was also associated with the incidence of eczema and allergic rhinitis in childhood. In contrast, no association was found between RsaI-in2 polymorphism and atopic asthma.

\section{Acknowledgments}

The authors thank Dr. Mohcene Djamel and Hanan Benslimane for their excellent technical assistance. They also thank Huda Driouche for the manuscript revision and editing.

\section{Funding}

This study was supported by funding from the Fonds Emile Beaulieu, Laval University Foundation to Dr. Rouabhia and the Algerian government.

\section{Author's Contributions}

Dahbia Ines: Performed the research collected the dada, analyzed the data and contribute writing the manuscript and its revision.

Nore-eddine Abadi, Mahmoud Rouabhia and Jamila Chakir: Designed the research study, contributed essential reagents and tools for molecular analysis, supervised the data collection and analysis, contributed manuscript preparation and revisions.

Ikhlass Haj Salem: Supervised the molecular biology experiments (Rt-PCR), contributed manuscript revision.

Karima Sifi: Designed the research study and $\operatorname{IgE}$ testing. 
Sara Malki and Laila Rouabah: Contributed patient recruitment and diagnosis.

Mohamed Bougrida: Designed the research study and contributed patient diagnosis.

Hacene Mehdioui: Contributed essential reagents of IL-4 testing.

Mounir Zhary Bachtarzi: Diagnostic of allergy and the realization of skin prick test.

Sellami abderrahim: Analysed the data.

\section{Ethics}

All authors declare no conflict of interest.

\section{References}

Asamoah, F., A. Kakourou, S. Dhami, S. Lau and I. Agache, 2017. Allergen immunotherapy for allergic asthma: A systematic overview of systematic reviews. Clin. Trans. Allergy., 2: 7-25.

Baldaçara, R.P. and I. Silva, 2017. Association between asthma and female sex hormones. Sao Paulo Med. J., 135: 4-14. DOI: 10.1590/1516-3180.2016.011827016

Bantz, S.K., Z. Zhu and T. Zheng, 2014. The atopic march: Progression from atopic dermatitis to allergic rhinitis and asthma. J. Clin. Cell Immunol.

Bateman, E.D., S.S. Hurd, P.J. Barnes, J. Bousquet and J.M. Drazen et al., 2008. Global strategy for asthma management and prevention: GINA executive summary. Eur. Respir. J., 31: 143-178.

Baxter, R.P., N. Lewis, B. Fireman, J. Hansen and N.P. Klein et al., 2017. Live attenuated influenza vaccination prior to age 3 years and subsequent development of asthma: A 14-year follow-up study. Pediatr Infect. Dis. J.

Bijanzadeh, M., P.A. Mahesh and N.B. Ramachandra, 2011. An understanding of the genetic basis of asthma. Indian J. Med. Res., 134: 149-161.

Bonnelykke, K., O. Raaschou-Nielsen, A. Tjonneland, C.S. Ulrik and H. Bisgaard et al., 2015. Postmenopausal hormone therapy and asthma-related hospital admission. J. Allergy Clin. Immunol., 135: 813-6.e5. DOI: 10.1016/j.jaci.2014.11.019

Bousquet, J. and W.W. Busse, 2010. Section 1. EPR-3 versus GINA 2008 guidelines-asthma control and step 3 care: Highlights of the asthma summit 2009: Beyond the guidelines. World Allergy Organ J., 3: 16-22.

Brożek, J.L., J. Bousquet, C.E. Baena-Cagnani, S. Bonini and G.W. Canonica et al., 2010. Allergic Rhinitis and its Impact on Asthma (ARIA) guidelines. J. Allergy Clin. Immunol., 126: 466-476.

Casale, T.B and Z. Marom, 1983. Mast cells and asthma: The role of mast cell mediators in the pathogenesis of allergic asthma. Ann. Allergy., 51: 2-6.
Castro, J., J.J. Telleria, A. Blanco-Quirós, P. Linares and R. Andion, 1998. Lack of association between atopy and RsaI polymorphism within intron 2 of the Pc\&RI- $\beta$ gene in a Spanish population sample. Allergy, 53: 1083-1086.

Chan, I.H.S., N.L.S. Tang, T.F. Leung, W. Huang and Y.Y.O. Lam et al., 2008. Study of gene-gene interactions for endophenotypic quantitative traits in Chinese asthmatic children. Allergy, 63: 1031-1039.

Choi, I.S., 2011. Gender-specific asthma treatment. Allergy Asthma Immunol. Res., 3: 74-80.

de Guia, R.M and J.D.A. Ramos, 2010. The -590C/TIL4 single-nucleotide polymorphism as a genetic factor of atopic allergy. Int. J. Mol. Epidemiol. Genet., 1: 67-73.

Dratva, J., 2010. Use of oestrogen only hormone replacement therapy associated with increased risk of asthma onset in postmenopausal women. Evid. Based Med., 15: 190-1.

Enright, P.L., R.L. McClelland, A.B. Newman et al., 1999. Underdiagnosis and undertreatment of asthma in the elderly. Cardiovascular Health Study Res. Group. Chest., 116: 603-613.

Fiuza, B.S.D., M.J. Silva, N.M. Alcântara-Neves, M.L. Barreto and R.D.S. Costa et al., 2017. Polymorphisms in DENND1B gene are associated with asthma and atopy phenotypes in Brazilian children. Mol. Immunol., 90: 33-41.

Fukao, T., H. Kaneko, T. Teramoto, H. Tashita and N. Kondo, 1996. Association between Fc epsilon RI beta and atopic disorder in a Japanese population? Lancet.

Fuseini, H. and D.C. Newcomb, 2017. Mechanisms driving gender differences in asthma. Curr. Allergy Asthma Rep., 17: 19-19.

Gelmetti, C., F. Boralevi, S. Seité, R. Grimalt and P. Humbert et al., 2012. Quality of life of parents living with a child suffering from atopic dermatitis before and after a 3-month treatment with an emollient. Pediatr Dermatol., 29: 714-8.

Hanania, N.A., M.J. King, S.S. Braman, C. Saltoun and R.A. Wise et al., 2011. Asthma in the elderly: Current understanding and future research needs--A report of a National Institute on Aging (NIA) workshop. J. Allergy Clin. Immunol., 128: S4-S24. DOI: $10.1016 /$ j.jaci.2011.06.048

Heinzerling, L., A. Mari, K.C. Bergmann, M. Bresciani and G. Burbach et al., 2013. The skin prick testEuropean standards. Clin. Transl. Allergy., 3: 2-10.

Hiletework, M., 2009. Evaluation of hanifin and rajka atopic eczema diagnostic guidelines for reduced minor criteria. Ethiop Med. J., 47: 39-47.

Hizawa, N., E. Yamaguchi, K. Furuya, N. Ohnuma and N. Kodama et al., 1995. Association between high serum total IgE levels and D11S97 on chromosome 11q13 in Japanese subjects. J. Med. Genet, 32: 363-369. 
Hizawa, N., Y. Maeda, S. Konno, Y. Fukui and D. Takahashi et al., 2006. Genetic polymorphisms at FCER1B and PAI-1 and asthma susceptibility. Clin. Exp. Allergy, 36: 872-6.

Hong, G.U., J.K. Lim, N.G. Kim, J.H. Shin and J.Y. Ro, 2015. IgE and IgA produced by OX40-OX40L or CD40-CD40L interaction in B cells-mast cells reactivate FceRI or FcaRI on mast cells in mouse allergic asthma. Eur. J. Pharmacol., 754: 199-210.

Korzycka-Zaborowska, B., H. Zielińska-Bliźniewska, J. Miłoński and J. Olszewski, 2014. High-affinity IgE receptor gene polymorphism and allergic rhinitis in a Polish population. Otolaryngol Pol. Otolaryngol., 68: 196-199.

Korzycka-Zaborowska, B., J.M. Hopkin and P. Górski, 2004. Genetic variants of FceRI $\beta$ and Il-4 and atopy in a Polish population. Allergol Immunopathol., 32: 53-58.

Kynyk, J.A., J.G. Mastronarde and J.W. McCallister, 2011. Asthma, the sex difference. Curr. Opin. Pulm. Med., 17: 6-11.

Lee, C.H. and H.S. Yu, 2011. Biomarkers for itch and disease severity in atopic dermatitis. Curr. Probl. Dermatol., 41: 136-48.

Licari, A., I. Brambilla, M. De Filippo, D. Poddighe and R. Castagnoli et al., 2017. The role of upper airway pathology as a co-morbidity in severe asthma. Expert Rev. Respir Med.

DOI: $10.1080 / 17476348.2017 .1381564$

Melgert, B.N., A. Ray, M.N. Hylkema, W. Timens and D.S. Postma, 2007. Are there reasons why adult asthma is more common in females? Curr. Allergy Asthma Rep., 7: 143-150.

Mersha, T.B., 2015. Mapping asthma-associated variants in admixed populations. Front Genet., 6: 292-292.

Miller, M.R., J. Hankinson, V. Brusasco, F. Burgos and R. Casaburi et al., 2005. ATS/ERS Task Force. Standardisation of spirometry. Eur. Respir. J., 26: 319-38.

Miller, S.A., D.D. Dykes and H.F. Polesky, 1988. A simple salting out procedure for extracting DNA from human nucleated cells., Nucleic Acids Res., 16: $12-15$.

Moorman, J.E., R.A. Rudd, C.A. Johnson, M. King and P. Minor et al., 2007. National surveillance for asthma--United States, 1980-2004. MMWR Surveill Summ., 56: 1-54.

Pinto, L.A., R.T. Stein and M. Kabesch, 2008. Impact of genetics in childhood asthma. J. Pediatr (Rio J)., 84: S68-75.

Rabe, K.F., W.J. Calhoun, N. Smith and P. Jimenez, 2001. Can anti-IgE therapy prevent airway remodeling in allergic asthma? Allergy, 66: 1142-51.
Rava, M., I. Ahmed, M. Kogevinas, N. Le Moual and E. Bouzigon et al., 2017. Genes interacting with occupational exposures to low molecular weight agents and irritants on adult-onset asthma in three European studies. Environ Health Perspect., 125: 207-214.

Report TGA, 2014. Global burden of disease due to Asthma, 2014.

Rochat, M.K., S. Illi, M.J. Ege, S. Lau and T. Keil et al., 2010. Multicentre Allergy Study (MAS) group: Allergic rhinitis as a predictor for wheezing onset in school-aged children. J. Allergy Clin. Immunol., 126: 1170-1175.

Shaaban, R., M. Zureik, D. Soussan, C. Neukirch and J. Heinrich et al., 2008. Rhinitis and onset of asthma: A longitudinal population-based study. Lancet, 372: 1049-1057.

Shirakawa, T., A. Li, M. Dubowitz , J.W. Dekker and A.E. Shaw et al., 1994. Association between atopy and variants of the $\beta$ subunit of the high-affinity immunoglobulin E receptor. Nat Genet., 7: 125-130.

Spergel, J.M., 2010. From atopic dermatitis to asthma: The atopic march. Ann Allergy Asthma Immunol Publ Am. Coll Allergy Asthma Immunol., 105: 99-106.

Suurmond, J., K.L.L. Habets, Z. Tatum, J.J. Schonkeren and P.A.C. Hoen et al., 2016. Repeated FceRI triggering reveals modified mast cell function related to chronic allergic responses in tissue. J. Allergy Clin. Immunol., 138: 869-880

Terada, T., T. Takahashi, H. Arikawa and S. Era, 2016. Analysis of the conformation and thermal stability of the high-affinity $\operatorname{IgE} \mathrm{Fc}$ receptor $\beta$ chain polymorphic proteins. Biosci Biotechnol Biochem., 80: 1356-1361.

Terry, D., S. Robins, S. Gardiner, R. Wyett and M.R. Islam, 2010. Asthma hospitalisation trends from 2010 to 2015: variation among rural and metropolitan Australians. BMC Public Health, 18: 723-723.

Van Hage-Hamsten, M., E. Johansson, M. Kronqvist, A. Loughry and W.O. Cookson et al., 2002. Associations of Fc epsilon R1-beta polymorphisms with immunoglobin $\mathrm{E}$ antibody responses to common inhalant allergens in a rural population. Clin. Exp. Allergy, 32: 838-42.

Vasiadi, M., D. Kempuraj, W. Boucher, D. Kalogeromitros and T.C. Theoharides, 2006. Progesterone inhibits mast cell secretion. Int. J. Immunopathol. Pharmacol., 19: 787-794.

Young, R.P., B.J. Hart, T.G. Merrett, A.F. Read and J.M. Hopkin, 1992. House dust mite sensitivity: Interaction of genetics and allergen dosage. Clin. Exp. Allergy, 22: 205-211. 